\title{
Rehabilitación estructural de un sector afectado por corrosión severa en vigas de entrepiso en una curtiembre
}

\author{
S. Peirén Cascino ${ }^{1 .}$
}

${ }^{1}$ Avenida Salto 1262 Paysandu, Uruguay.

\begin{abstract}
Información del artículo
DOI:

http://dx.doi.org/10.21041/ra.v1 $\underline{i 3.18}$

Artículo recibido el 11 de Abril de 2011, revisado bajo las políticas de publicación de la Revista ALCONPAT y aceptado el 01 de Julio de 2011.

Cualquier discusión, incluyendo la réplica de los autores se publicará en el segundo número del 2012 siempre y cuando la información se reciba antes del cierre del primero de 2012
\end{abstract}

(C) 2011 Alconpat Internacional

Información Legal

Revista ALCONPAT, Año 1, No. 3 , Septiembre - Diciembre 2011, es una publicación cuatrimestral de la Asociación Latinoamericana de Control de Calidad, Internacional, A.C., Km. 6, antigua carretera a Internacional, A.C., Km. 6, antigua carres. Tel.5219997385893, alconpat.int@gmail.com Página Web: www.alconpat.org Editor responsable: Dr. Pedro Castro Borges. Reserva de derechos al uso exclusivo No.042013-011717330300-203, eISSN 2007-6835, ambos otorgados por el Instituto Nacional de Derecho de Autor. Responsable de la última actualización de este número, Unidad de actualización de este número, Unidad de Maldonado, Km. 6, antigua carretera a Progreso, Mérida Yucatán, C.P. 97310 , fecha de publicación: 30 de septiembre de 2011

Las opiniones expresadas por los autores no necesariamente reflejan la postura del editor Queda totalmente prohibida la reproducción total o parcial de los contenidos e imágenes la publicación sin previa autorización
ALCONPAT Internacional A.C.

\section{RESUMEN}

La caída al vacío de parte del fondo de una viga ubicada a $6.00 \mathrm{~m}$ de altura, motivó la realización del diagnóstico y proyecto de rehabilitación de un sector de una planta industrial ubicada en la ciudad de Paysandú - Uruguay.

El objetivo de este trabajo es exponer un caso real que permita evitar reparaciones ineficientes que pueden generar riesgos para las personas.

La inspección visual y la revisión de los antecedentes revelaron que este sector ya había sido intervenido anteriormente, favoreciendo la corrosión de la armadura y el agrietamiento interno de los elementos estructurales, que provocaron el desprendimiento parcial del hormigón.

Los recubrimientos de armadura insuficientes sumados a la atmósfera industrial corrosiva, generaron las patologías que se detallan en el presente trabajo.

Palabras clave: rehabilitación; patología; corrosión; estructura.

\section{ABSTRACT}

The fall of part of a beam located at $6 \mathrm{~m}$ of height led to a diagnosis and rehabilitation project within an area of an industrial plant in Paysandú, Uruguay.

The aim of this work is to show a case study that would allow avoiding future risky inefficient repairs. A visual inspection and an analysis of the background of the problem revealed that a previous intervention had taken place, which favored the corrosion of the reinforcement and internal cracking of the structural elements; such factors caused partial spalling of the concrete. The causes of the pathologies described in this report were originated by inadequate coating of the reinforcement as well as the corrosive industrial environment.

Key words: rehabilitation; pathology; corrosión; structure.

Autor de contacto: Soledad Peirén Cascino (solpe@ adinet.com.uy) 
Revista ALCONPAT, Volumen 1, Número 3, Septiembre-Diciembre 2011, Páginas 225 - 232

\section{INTRODUCCION}

La intervención tuvo lugar en la ribera de una Planta Industrial ubicada en la ciudad de Paysandú - Uruguay, donde se realiza el curtido de cueros en fulones que se cargan por la parte superior a través de huecos conformados en el entrepiso para tal fin, y se descargan desde planta baja una vez terminado el proceso.

Los vapores cargados de agentes agresivos generados en el proceso de curtido, el vapor húmedo a alta temperatura producto de la limpieza del sector luego de cada uso del fulón, sumados a la inexistencia de ventilación, provocaron las patologías constatadas que se describen más adelante. La estructura consiste en un entrepiso de losas alivianadas, de espesor total $0.53 \mathrm{~m}$, sustentado por vigas y pilares de distintas secciones. En el presente trabajo se describirán las intervenciones realizadas en las vigas $\mathrm{N}^{\circ} 15 \mathrm{y} \mathrm{N}^{\mathrm{o}} 21$ del Sector $\mathrm{N}^{\circ} 9$.

\section{BARANDA DE HORMIGON}

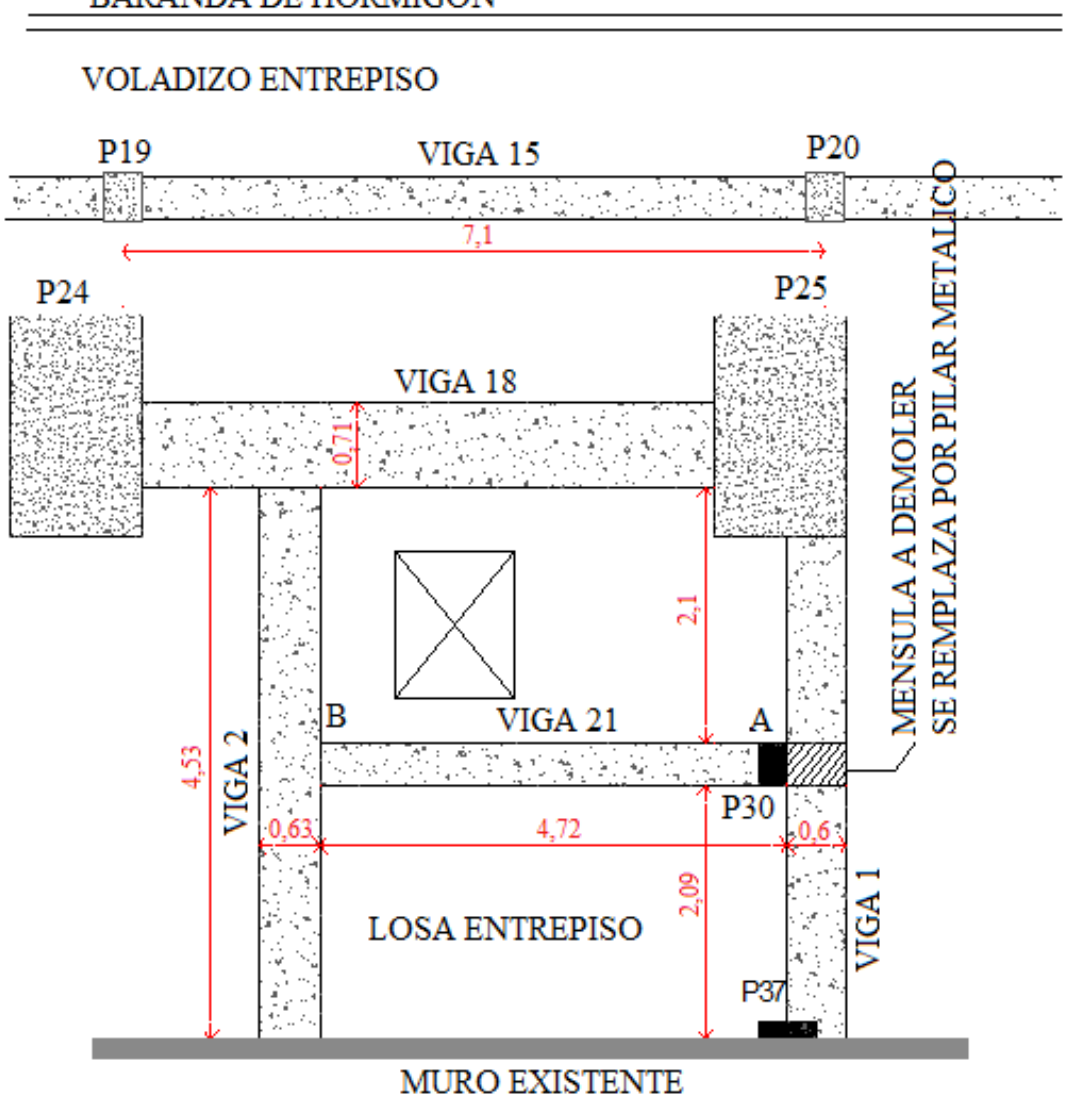

Figura 1. Planta del entrepiso del sector $\mathrm{N}^{\circ} 9$

\section{ESTADO DE LA ESTRUCTURA.}

En la inspección visual realizada inmediatamente posterior al desprendimiento de parte de la reparación de la viga $\mathrm{N}^{\mathrm{o}} 15$ próxima a la circulación, se advierte que aún persistía hormigón agrietado prácticamente desprendido, que se precipitó por completo al tocarlo con una pértiga.

En general, la superficie expuesta de losas y vigas tenía manchas de corrosión localizadas. (Figuras 2 y 3 ). 

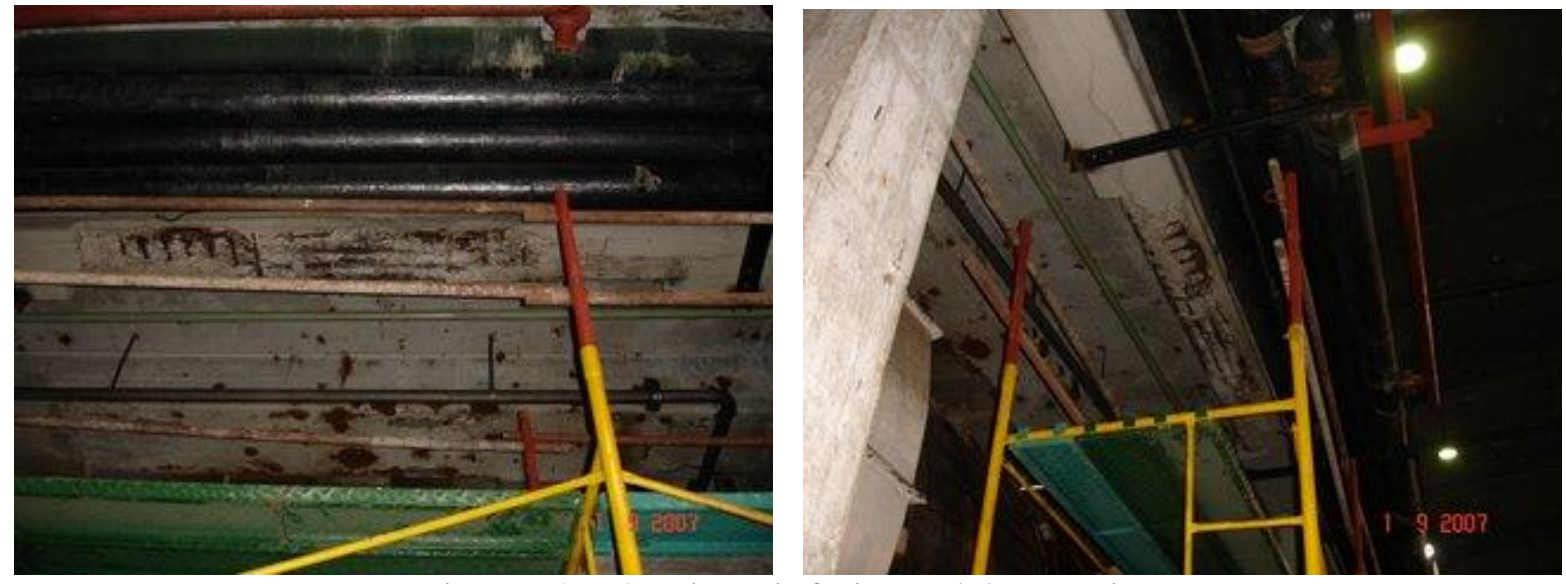

Figuras 2 y 3 . Vistas inferiores del entrepiso

Reparaciones anteriores en forma de $\mathrm{U}$ de $0.08 \mathrm{~m}$ de espesor, en la zona inferior, con agrietamientos (Figuras 4 y 5).
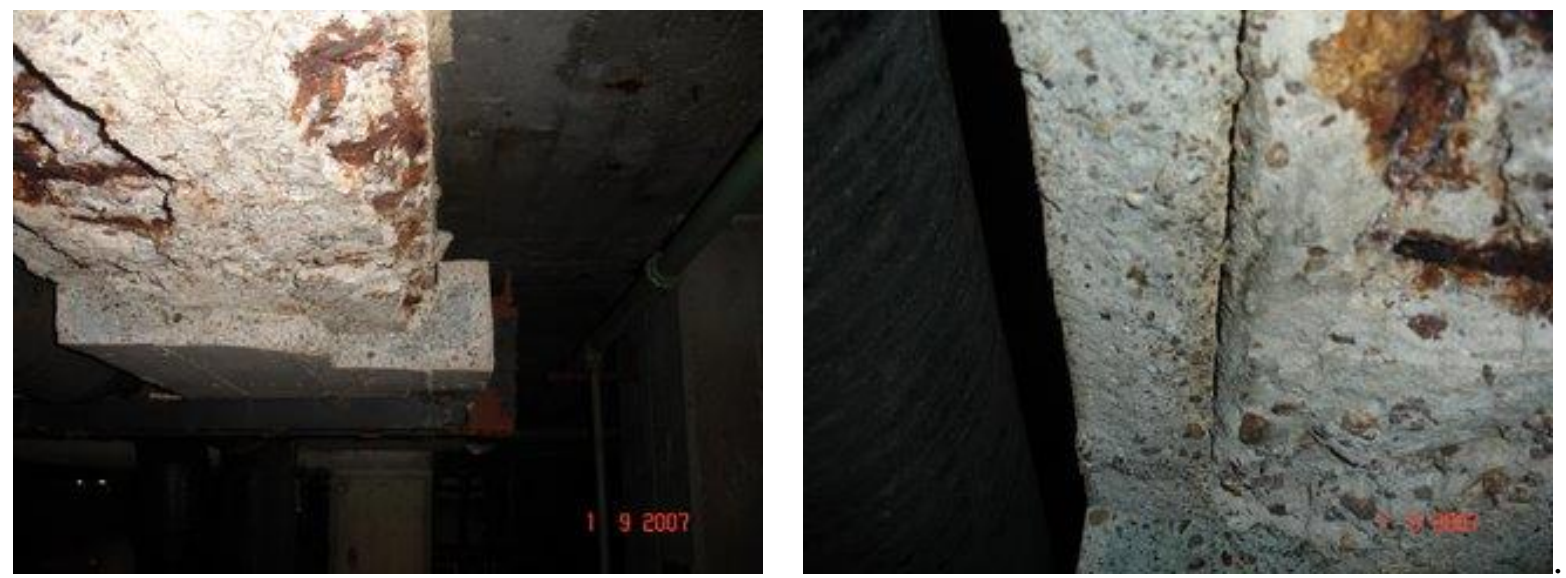

Figuras 4 y 5. Reparación anterior que evidencia la falta de intervención en las vigas afectadas

\section{REVISIÓN DE ANTECEDENTES}

Del cotejo de los recaudos gráficos existentes surge que, por su ubicación, la viga de referencia es la $\mathrm{N}^{\mathrm{o}} 15$, de 7,10 m de luz entre ejes de pilares, aunque la viga ejecutada en su lugar no coincide ni en sección ni armadura con lo indicado en los mismos. En su lugar se ejecutó una viga de las mismas características que la viga $\mathrm{N}^{\circ} 16$. (Tabla 1)

Tabla 1. Datos de recaudos gráficos disponibles

\begin{tabular}{|l|c|c|c|c|c|}
\cline { 2 - 6 } \multicolumn{1}{c|}{} & SECCION & HIERROS A & HIERROS B & HIERROS E & ESTRIBOS \\
\hline VIGA N $15^{\circ}$ & $25 \times 130$ & $5 \varnothing 25$ & $6 \varnothing 25$ & $3 \varnothing 16$ & Uø10/20 \\
\hline VIGA N $16^{\circ}$ & $35 \times 100$ & $4 \varnothing 25$ & $5 \varnothing 25$ & $3 \varnothing 16$ & Uø10/20 + 26U12/12 \\
\hline
\end{tabular}

No existen antecedentes gráficos ni escritos de la intervención anterior, que fue realizada aprox. en el año 2002 en oportunidad de una obra de ampliación de la planta. 
Revista ALCONPAT, Volumen 1, Número 3, Septiembre-Diciembre 2011, Páginas 225 - 232

De la inspección ocular surge que esta reparación no quedó adherida a la masa de hormigón existente, y a través de estas luces se permitió el pasaje de la atmosfera contaminada que aumentó el deterioro de las vigas. (Figura 4)

Se constatan grietas profundas en el hormigón como consecuencia de corrosión avanzada en armadura principal, faltantes de estribos en la zona central de la viga, y existencia de tramos de armadura principal utilizados como separadores transversales. (Figuras 5 y 6 ).
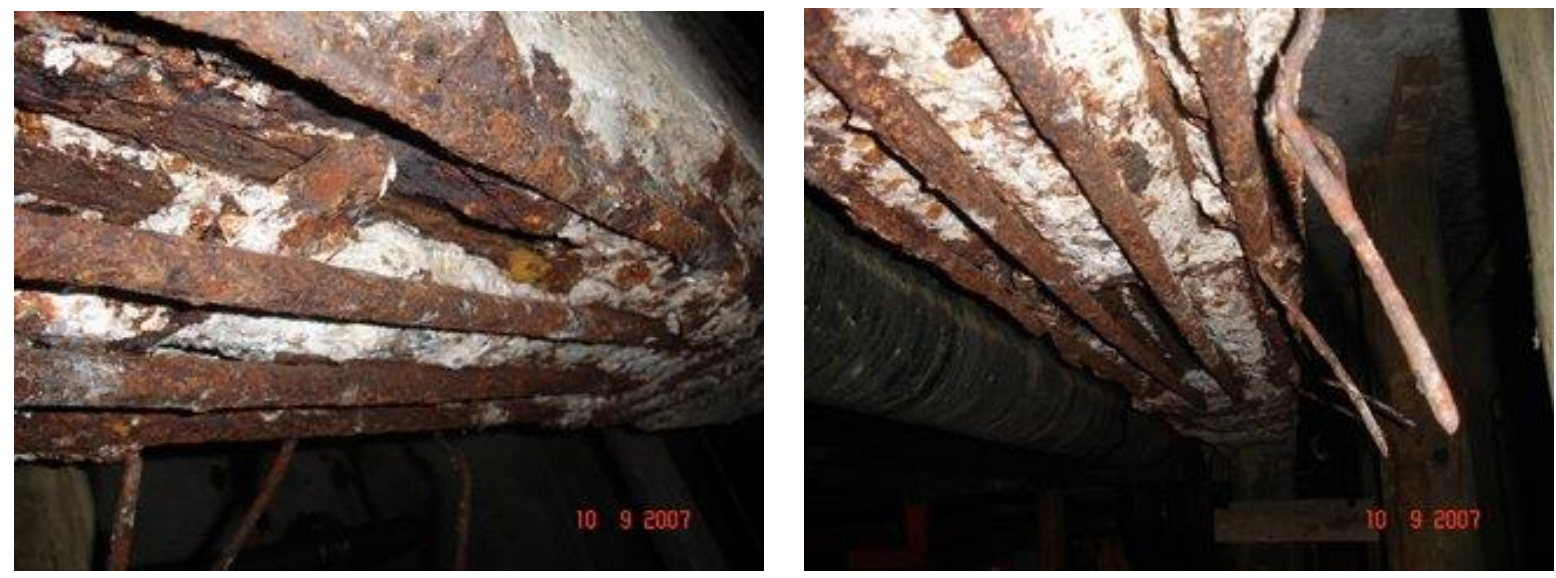

Figuras 5 y 6 . Estado de la Viga $\mathrm{N}^{\circ} 15$ previo a su reparación

Previo al inicio de los trabajos, se apuntaló la losa contigua a la viga, hacia el interior del sector; ante la imposibilidad de apuntalar el voladizo por la existencia de cañerías instaladas cuyos fluídos alimentan la planta industrial en forma continua, y no se permitían desmontar, se apuntaló la viga por medio de 3 caños de hierro de ø 5 " cédula 40, rellenos de hormigón, equidistantes, que la atraviesan y la sostienen con pilares de iguales características arriostrados entre sí a la mitad de su altura como mínimo. (Figuras 7 y 8)
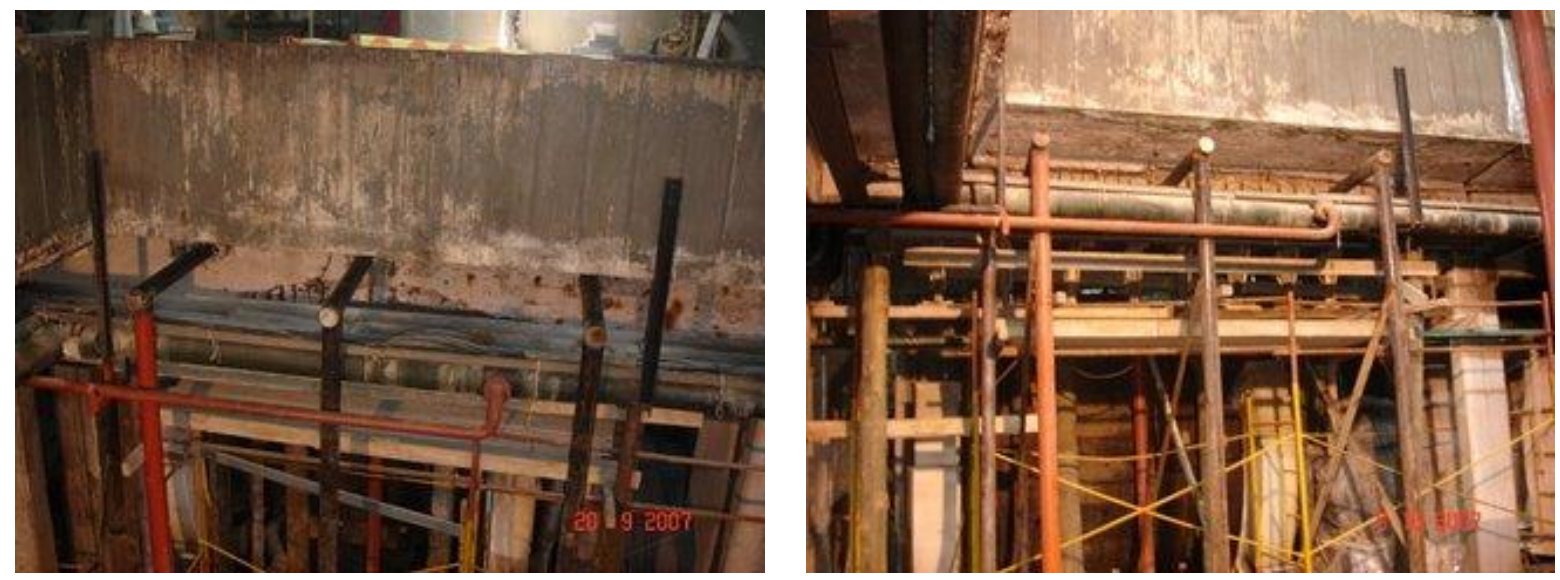

Figuras 7 y 8 . Apuntalamiento de la viga $\mathrm{N}^{\mathrm{o}} 15$

Una vez apuntalada la viga, se eliminó el hormigón afectado hasta descubrir la armadura principal y se picó el revestimiento lateral de la viga en coincidencia con los restos de los estribos, a los fines de descubrir la zona sana de los mismos para soldar los estribos de reposición.

Una vez repuestos los estribos faltantes (se sueldan $2 \varnothing 8$ en U, a cada lado del estribo sano existente), manteniendo en todo momento la horizontalidad de la armadura principal (Figura 9) 
Revista ALCONPAT, Volumen 1, Número 3, Septiembre-Diciembre 2011, Páginas 225 - 232

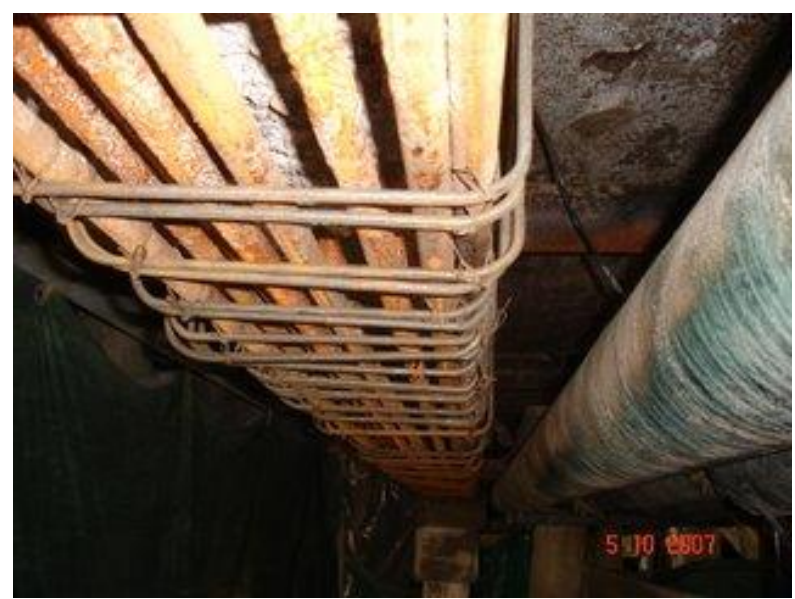

Figura 9. Reposición de estribos en viga $\mathrm{N}^{\circ} 15$

Se limpió toda la superficie resultante (hormigón y hierro) con un sistema de hidroarenado, y finalmente con agua a presión, con el objetivo de eliminar partículas sueltas y los productos de la corrosión acumulados sobre las varillas.

La armadura se limpió hasta que quedara gris, notando que en pocas horas comenzaba el proceso de oxidación producto del ambiente circundante (Figura 10).

Se agregó en el centro de la primera capa de armadura, $1 \varnothing 25$ a los efectos de compensar la pérdida general de sección de los $4 \varnothing 25$ de esa capa.

En uno de los extremos de la viga, donde los estribos y la armadura principal no habían sido afectados por la corrosión, se soldó una platina, y a ésta última la nueva armadura de refuerzo (Figura 11).

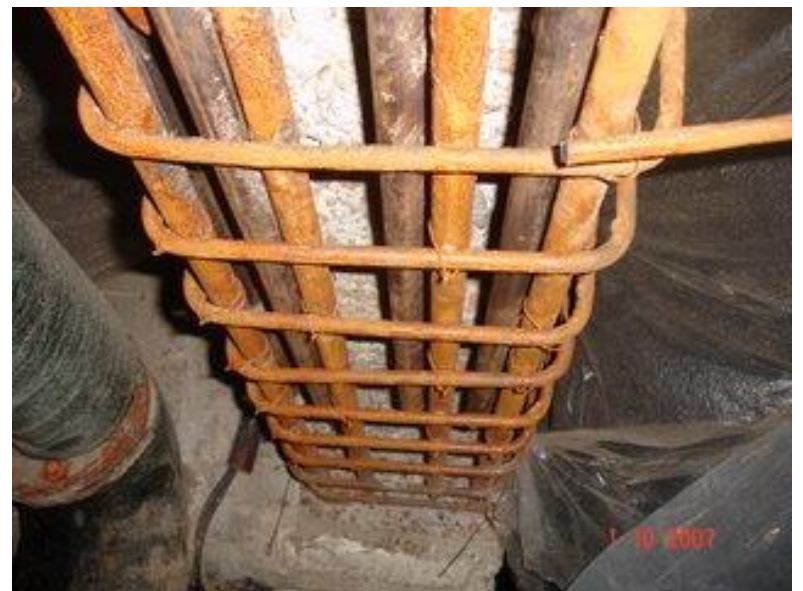

Figura 10. Extremo con estribos sanos

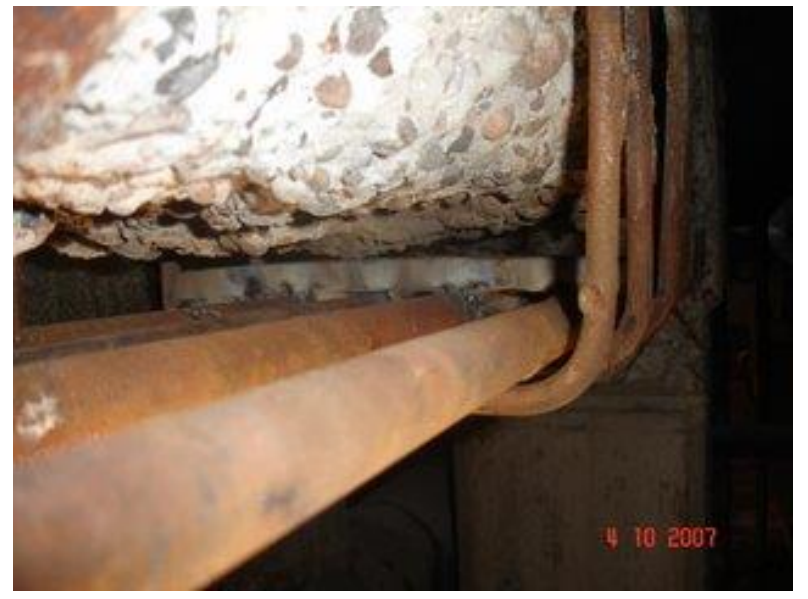

Figura 11. Platina soldada

Una vez seco el hormigón, se aplicó sobre la armadura, un revestimiento anticorrosivo como protector contra la corrosión de la armadura.

Para devolver la sección de hormigón a la viga, se conformó el encofrado asegurando un recubrimiento de $4 \mathrm{~cm}$.

Luego se realizó el colado de un mortero expansivo sin retracción con $40 \%$ de gravilla de hasta $\varnothing$ $2 \mathrm{~mm}$, siempre por el mismo lateral del encofrado, permitiendo que se expulse el aire por el lateral opuesto.

Al día siguiente, se retiran los encofrados laterales, y se continúa con el curado del hormigón. 
Revista ALCONPAT, Volumen 1, Número 3, Septiembre-Diciembre 2011, Páginas 225 - 232

En ambos laterales de la viga y sobre los estribos, se aplicó el puente de adherencia, y antes de transcurrido el tiempo por el adhesivo epóxico (Open Time) se aplicó un mortero de reparación a base de resinas epoxi en toda la superficie lateral dejándola pronta para pintar.

Se realizó un cateo en la losa sobre la zona superior de la viga afectada, a los efectos de determinar el estado de conservación de los hierros de la misma, y verificar la altura real de la viga, para realizar la comprobación estructural de la misma.

\section{VIGA N$^{\circ} 21$ y MENSULA SOPORTE DE VIGA No 1}

Una vez apuntalada la Viga $\mathrm{N}^{\circ}$ 1, a ambos lados de la ménsula, se eliminó toda la armadura de esta última (Figura 12), que presentaban un estado de corrosión avanzada, generando espacio para agregar 3 varillas de hierro tratado $\emptyset 19$ para compensar la pérdida de sección de la armadura principal existente en la viga $\mathrm{N}^{\mathrm{o}} 21$.

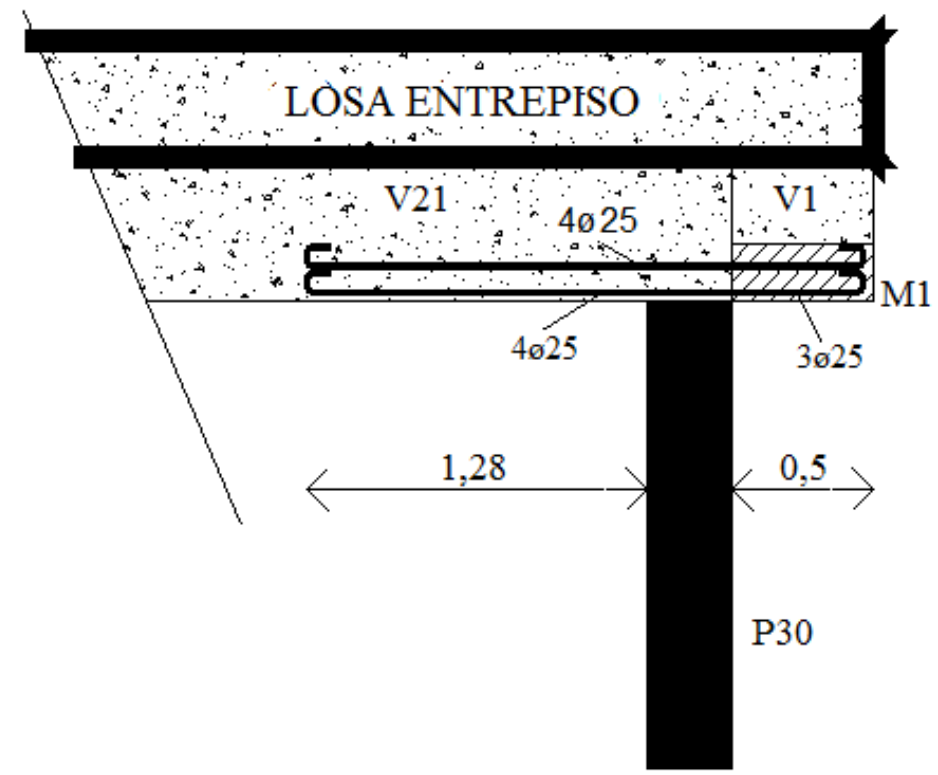

Figura 12. Detalle constructivo
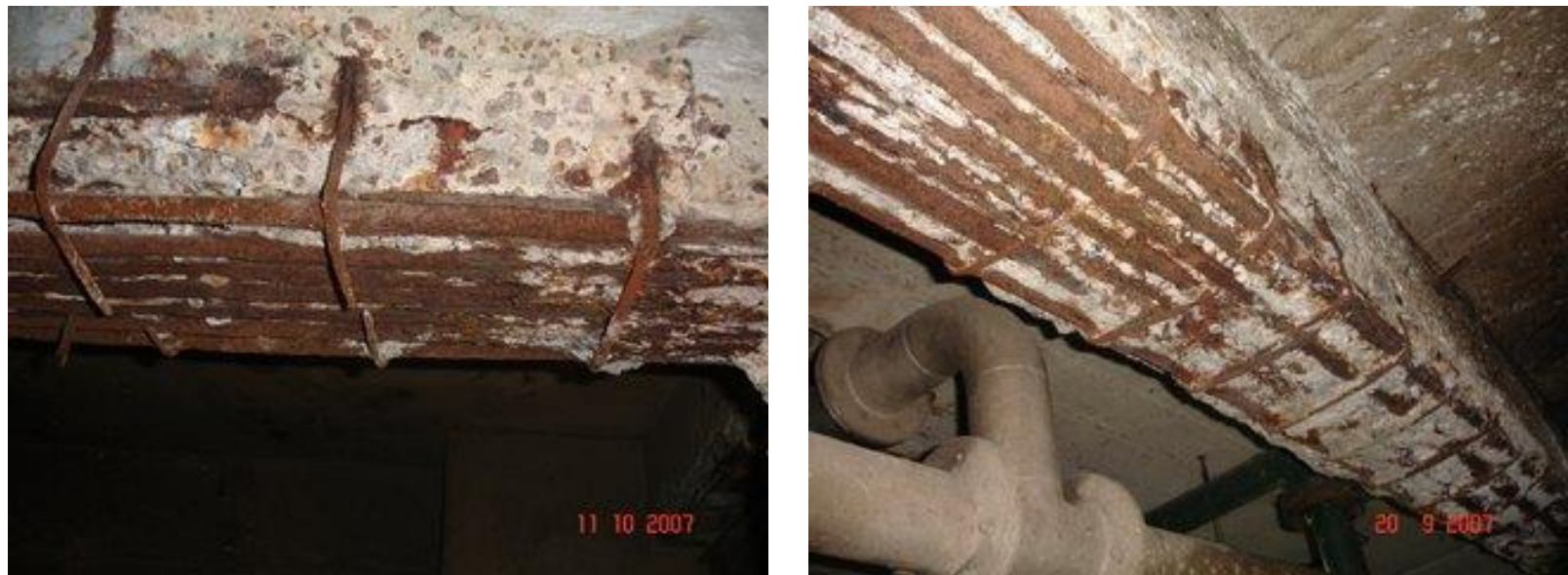

Figuras 13 y 14. Estado de la Viga $\mathrm{N}^{\circ} 21$ una vez eliminada la reparación anterior. 
Revista ALCONPAT, Volumen 1, Número 3, Septiembre-Diciembre 2011, Páginas 225 - 232

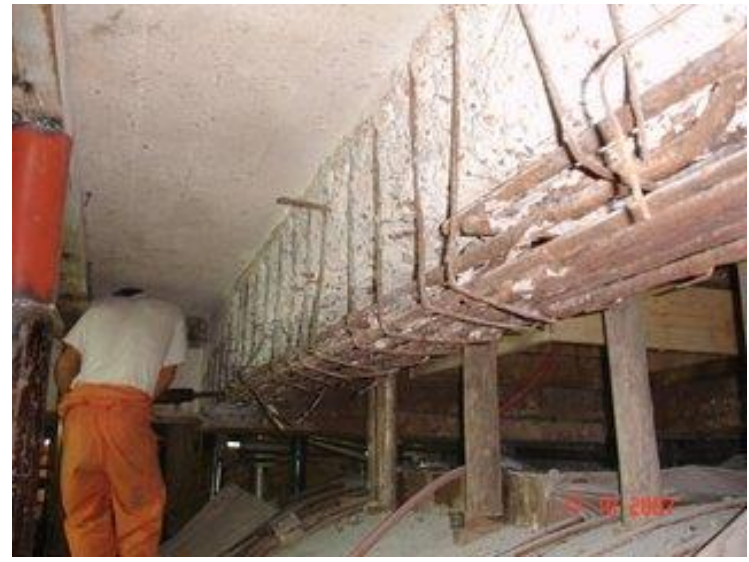

Figura 15. Eliminación mecánica del hormigón afectado en la viga № 21

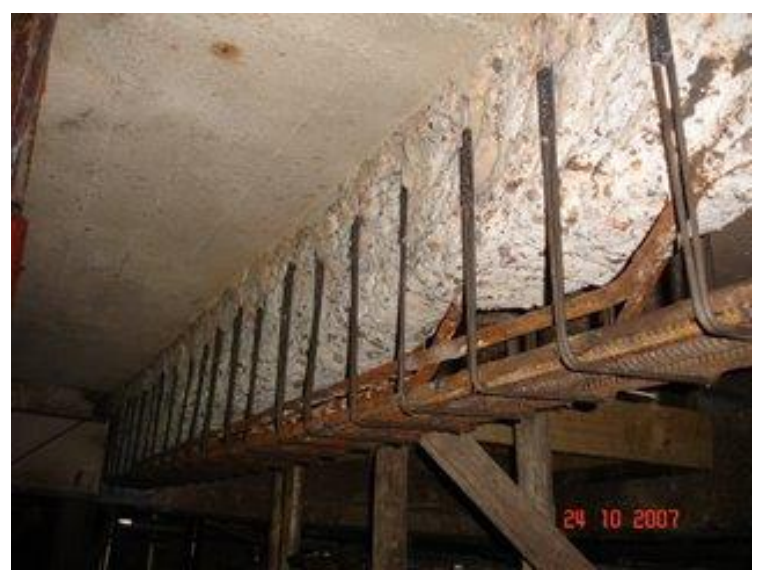

Figura 16. Viga $\mathrm{N}^{\mathrm{o}} 21$ después de la reposición de armadura principal y estribos.

En el extremo A, pilar $N^{\circ} 30$ (Figura 1), se practicaron perforaciones pasantes para introducir la nueva armadura evitando soldaduras, mientras que en el extremo B (Viga $\mathrm{N}^{\mathrm{o}} 2$ ), se amuró la misma con anclajes químicos hasta $15 \mathrm{~cm}$ de profundidad.

Para la reposición de estribos se procedió de igual forma que la indicada para la viga $\mathrm{N}^{\mathrm{o}} 15$
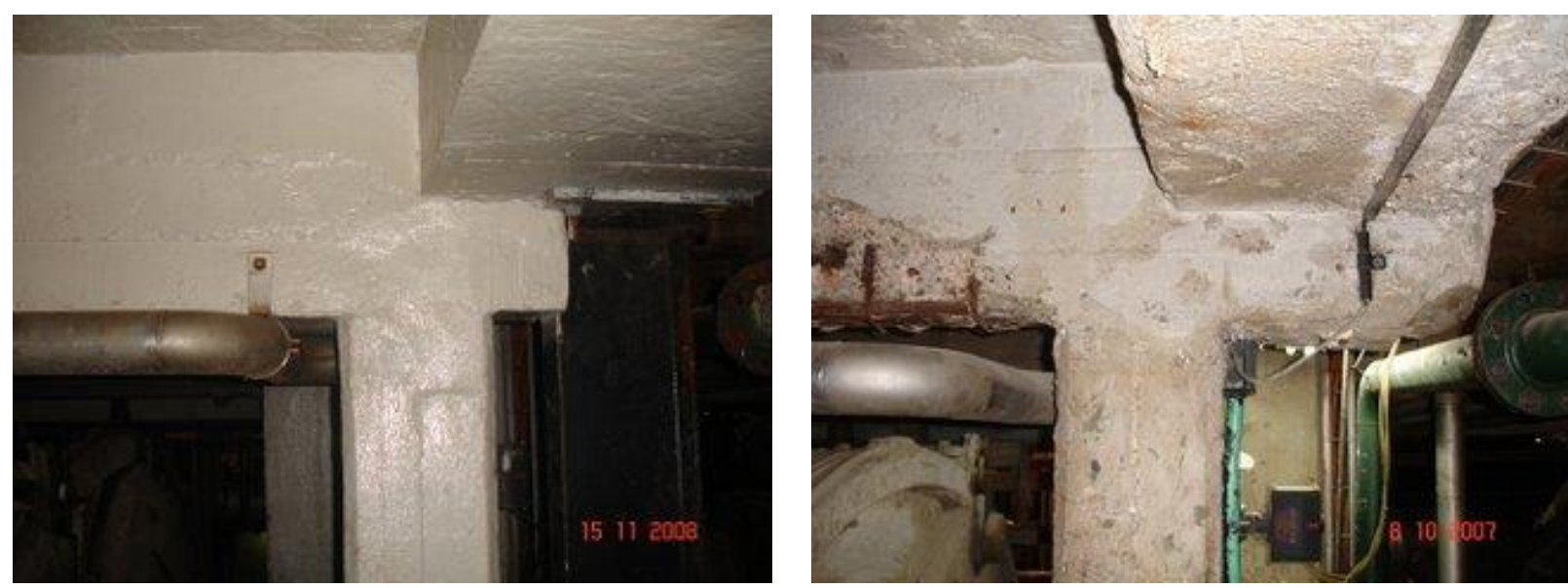

Figuras 17 y 18. Viga $\mathrm{N}^{\circ}$ 21, Pilar $\mathrm{N}^{\mathrm{o}} 30$ y Ménsula antes y después de la intervención

Una vez concluidos los trabajos en el resto de la estructura del fulón, se selló la superficie de hormigón expuesta, con 3 manos de pintura epóxica de alta resistencia a los agentes químicos, que ha dado buenos resultados a la fecha. 

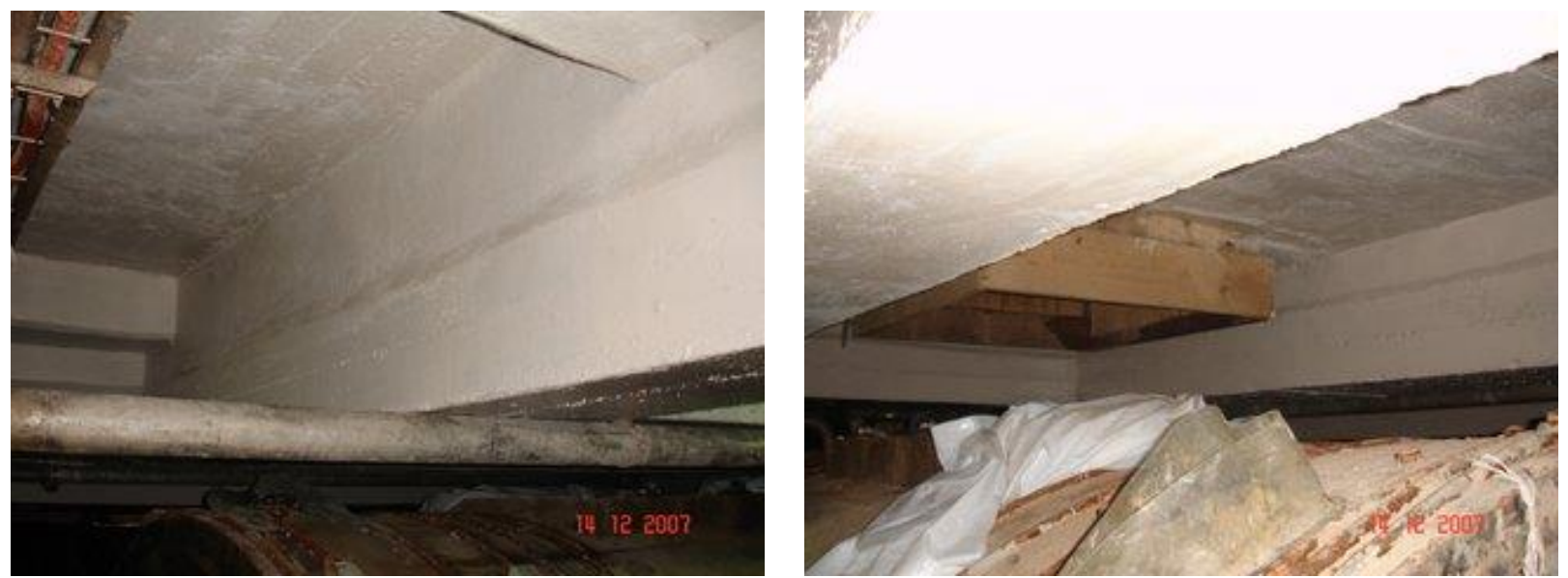

Figuras 19 y 20 . Vigas $\mathrm{N}^{\circ} 2,18$ y 21 luego de las reparaciones

En el resto de las vigas se realizó el mismo procedimiento que en la viga $\mathrm{N}^{\circ} 21$, sin el agregado de armadura principal.

\section{CONCLUSIONES}

Las reparaciones ineficientes realizadas con anterioridad, oportunidad en la que no fue saneada la armadura afectada ni el hormigón agrietado, aumentaron el deterioro de los distintos elementos estructurales.

La falta de ventilación del referido sector impide la evacuación de la alta agresividad del ambiente circundante, que está en contacto permanente con la estructura.

Todas las acciones que se tomen, ya sean correctivas o preventivas, no van a eliminar la posibilidad de aparición de corrosiones puntuales en el futuro. En los casos de aparición de síntomas, hay que intervenir con acciones correctivas nuevamente, para lo cual se recomienda que tanto las estructuras reparadas, como las que aún no han sido intervenidas, sean monitoreadas en forma periódica.

\section{RESULTADOS}

Todos los trabajos fueron realizados por una empresa constructora local, que si bien no había realizado anteriormente este tipo de reparaciones profundas ni utilizado los productos recomendados por la Dirección Técnica de las Obras, cumplió en tiempo y forma con el objeto del llamado.

Los Directivos de la Planta Industrial que inicialmente pensaron en reparar únicamente la viga con desprendimiento de masa, comprendieron la problemática y el riesgo que presentaba para sus operarios e inhabilitaron el fulón del sector de referencia para que éste fuera intervenido en su totalidad.

\section{REFERENCIAS}

CYTED (1997), Manual de Inspección, Evaluación y Diagnóstico de Corrosión en Estructuras de Hormigón Armado.

Helene P., Pereira F. (2007), Rehabilitación y Mantenimiento de Estructuras de Concreto. 